\title{
Pretreatment-assisted robot intrathoracic layered anastomosis: our exploration in Ivor-Lewis esophagectomy
}

\author{
Zhi-Jie Xu ${ }^{1 \#}$, Ze-Guo Zhuo ${ }^{1 \#}$, Tie-Niu Song ${ }^{1 \#}$, Gang Li ${ }^{1,2}$, Gu-Ha Alai ${ }^{1}$, Xu Shen ${ }^{1}$, Peng Yao ${ }^{1}$, Yi-Dan Lin ${ }^{1}$ \\ ${ }^{1}$ Department of Thoracic Surgery, West China Hospital, Sichuan University, Chengdu, China; ${ }^{2}$ Department of Thoracic Surgery, Hospital of \\ Chengdu Office of People's Government of Tibetan Autonomous Region, Chengdu, China \\ Contributions: (I) Conception and design: YD Lin, ZJ Xu; (II) Administrative support: YD Lin; (III) Provision of study materials or patients: YD Lin, \\ ZJ Xu; (IV) Collection and assembly of data: X Shen, P Yao; (V) Data analysis and interpretation: TN Song, ZG Zhuo, GH Alai; (VI) Manuscript \\ writing: All authors; (VII) Final approval of manuscript: All authors. \\ \#These authors contributed equally to this work. \\ Correspondence to: Yi-Dan Lin, MD, PhD. Department of Thoracic Surgery, West China Hospital, Sichuan University, No. 37 Guoxue Alley, \\ Chengdu 610041, China. Email: linyidan.academy@foxmail.com.
}

Background: Minimal invasive Ivor-Lewis esophagectomy (MIIVE) with intrathoracic esophago-gastric anastomosis (EGA) is still under exploration and the preferred technique for intrathoracic anastomosis has not been established.

Methods: We retrospectively reviewed 43 consecutive patients who underwent MIIVE using the series technique called pretreatment-assisted robot intrathoracic layered anastomosis (PRILA), performed by a single surgeon between September 2018 and December 2020. The operative outcomes were analyzed.

Results: The mean total operation time had been reduced from 446.38 54.775 minutes (range, 354-552) in the first year to $347.70 \pm 60.420$ minutes (range, 249-450) later. There were no conversions to thoracotomy. All the patients achieved R0 resection. No patient suffered from anastomotic leakage. There was no 30-day mortality. The median length of postoperative stay was 10.0 days.

Conclusions: PRILA further visualizes and streamlines the process of minimal invasive intrathoracic EGA, thus ensuring the precise anastomosis. It could be considered as a feasible alternative for intrathoracic EGA in MIILE.

Keywords: Robotic-assisted Ivor-Lewis esophagectomy; hand-sewn layered anastomosis; pretreatment of the gastric conduit and the esophagus

Submitted Mar 14, 2021. Accepted for publication Jun 19, 2021.

doi: $10.21037 /$ jtd-21-438

View this article at: https://dx.doi.org/10.21037/jtd-21-438

\section{Introduction}

Minimal invasive esophagectomy (MIE) has become the mainstream in esophageal cancer surgery for less surgical trauma and superior survival compared with open surgery $(1,2)$. At present, limited to the complexity of esophagogastric anastomosis (EGA), most MIE in China was performed via McKeown esophagectomy with cervical EGA $(3,4)$. However, for patients with lower-thoracic esophageal cancer, esophagogastric junction cancer and even some mid-thoracic esophageal cancer, which accounted for more than $80 \%$ of the total cases in China (5), minimal invasive Ivor-Lewis esophagectomy (MIILE) with intrathoracic EGA would be a better choice because the anastomosis site was lower and closer to the gastroepiploic arterial arcade. Patients with intrathoracic EGA would get better functional results with less posteroperative complications $(6,7)$.

With the help of the 3D visualization and improved maneuverability provided by da Vinci surgical system, some experienced surgeons have begun to try robotic-assisted 
Ivor-Lewis esophagectomy with intrathoracic EGA (8). However, the best manner for robot intrathoracic EGA was still controversial $(9,10)$, most of them adopted circularstapled anastomosis or linear-stapled anastomosis. During our early practice of using circular-stapler anastomosis, we found that inserting the circular stapler into the gastric tube and piercing the stapler spike through the wall of gastric conduit was complex limited to the narrow intercostal space, and the postoperative anastomotic stricture was more likely to occur after the circular-stapled anastomosis $(11,12)$. As for the linear-stapled anastomosis, it was necessary to ensure a certain length of the proximal esophageal stump, which limited this anastomotic technique to tumors located in the lower-thoracic esophagus and the esophagogastric junction (13). There were also several reports on robot hand-sewn intrathoracic EGA. But they only contained a small number of surgical cases and the technique of robot hand-sewn intrathoracic EGA was still under exploration without wide acceptation (14-19).

Based on our extensive experience of three-leaf clipperassisted hand-sewn layered anastomosis in open surgery (11), we developed this series technique called pretreatmentassisted robot intrathoracic layered anastomosis (PRILA), making robot intrathoracic EGA more precise and more fluent. In this study, we report our early experience in MIILE using PRILA and describe the technical innovations made in response to intraoperative challenges.

We present the following article in accordance with the STROBE reporting checklist (available at https://dx.doi. org/10.21037/jtd-21-438).

\section{Methods}

The study population was a consecutive series of patients undergoing PRILA with curative intent for a biopsy proved esophageal malignancy in Department of Thoracic Surgery, West China Hospital, Sichuan University, from September 2018 to December 2020. All surgeries were performed by the same surgical team led by the corresponding author of this paper (LYD).

The exclusion criteria were: (I) the position of the upper edge of the tumor was above the level of azygos vein; (II) patients with cT4b disease evaluated by enhanced computed tomography; (III) patients with distant metastasis; (IV) patients with a history of gastrointestinal or thoracic surgery. The study was conducted in accordance with the Declaration of Helsinki (as revised in 2013) and was approved by the Ethics Committee of the West China
Hospital of Sichuan University (No. 2020-323). Informed consent to undergo robotic surgery was obtained from all patients.

\section{Operative techniques}

\section{Laparoscopic abdominal procedure}

The abdominal stage was done by laparoscopy. The patients were placed in the reverse Trendelenburg position and artificial $\mathrm{CO}_{2}$ pneumoperitoneum was established to a pressure of $12 \mathrm{mmHg}$. Five ports were used. One $12 \mathrm{~mm}$ trocar was placed in the umbilicus for camera, another two $12 \mathrm{~mm}$ trocars were placed at the right and left midclavicular line, below the costal arch, respectively. One $5 \mathrm{~mm}$ trocar was placed at the left anterior axillary line, below the costal arch. One $12 \mathrm{~mm}$ trocar was placed 3 to $4 \mathrm{~cm}$ distal to the xiphoid for the liver retractor. A radical "en bloc" lymphadenectomy was completed while gastric mobilization. Divide the stomach from the cardia using a linear stapler.

\section{Pretreatment of the gastric conduit}

Then the stomach was pulled out of the abdominal cavity through a $5.0 \mathrm{~cm}$ incision by extending the liver retractor port. A $4 \mathrm{~cm}$-wide gastric conduit was constructed using a linear stapler (EC60G, J\&J, USA). To estimate the anastomotic site on the gastric conduit, the gastric conduit was outspreaded along the anterior median line of the patient, and the part beyond the sternal angle was transected (Figure 1A). This tailoring method not only ensured the required length of the gastric conduit for intrathoracic anastomosis, but also removed the gastric fundus with poor blood supply. Then, the gastrostomy site was chosen on the anterior wall of the highly vascularized gastric conduit about $0.5 \mathrm{~cm}$ to the distal end and sewed a marked thread here. The diameter of the gastrostomy was tailored to match the intra-luminal diameter of the esophagus which had already been estimated during the mobilization of the abdominal esophagus. Incised only the seromuscular layer of the gastric conduit while keeping the submucosa and mucosa intact (Figure 1B). Then, the gastric conduit was carefully packaged with single-layered warm wet gauze which was tied using $7 \#$ silk thread and their knots were directed to mark the gastroepiploic arterial arcade (Figure 1C). So when we pulled the gauze into the thorax, the gastric conduit would come along with it avoiding being directly grasped and pulled directly by surgical instruments, the risk of damaging the fragile 

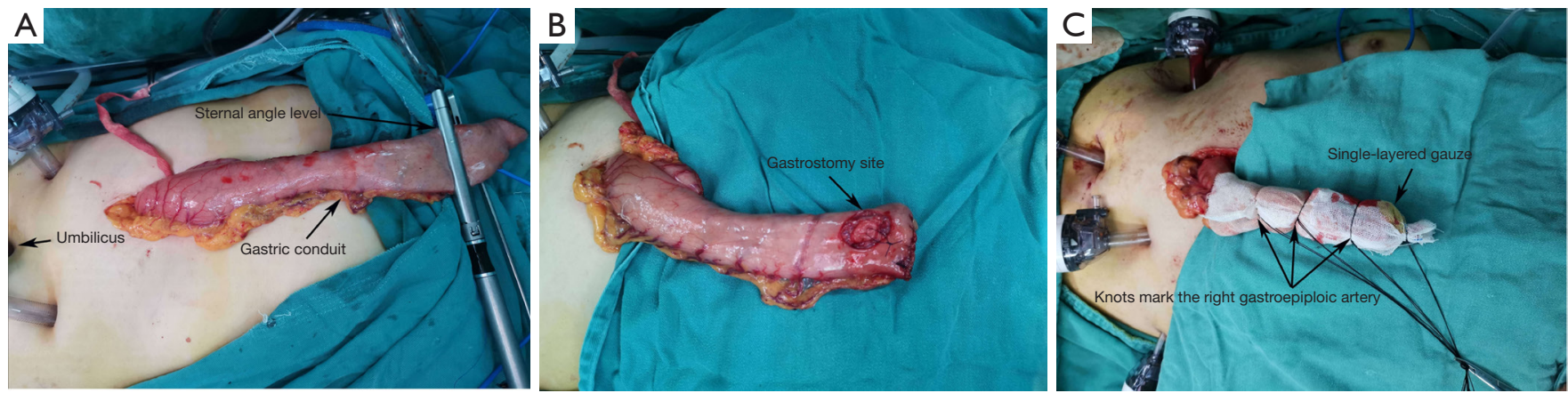

Figure 1 Pretreatment of the gastric conduit. (A) The gastric conduit was outspreaded along the anterior median line of the patient and the part beyond the sternal angle was transected; (B) sew a marked thread at the site of gastrostomy and only incise the gastric seromuscular layer; $(\mathrm{C})$ package the gastric conduit using single-layered gauze. $7 \#$ silk threads were used to moderately tighten the package and the knots were made on the gauze along the right gastroepiploic artery to mark this artery.

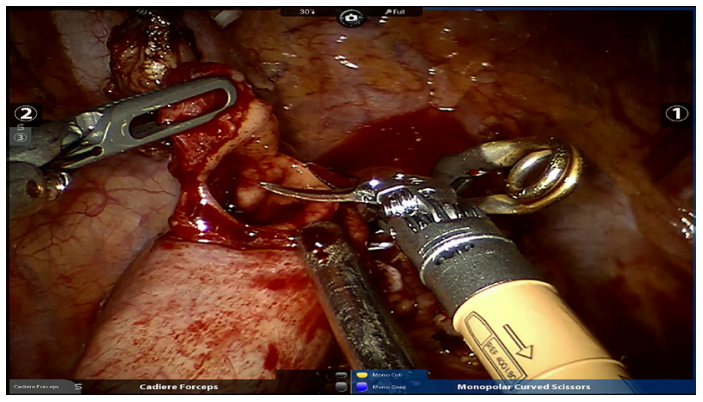

Figure 2 The mucosal layer of gastric conduit was incised with robotic scissors with its electronic coagulation function being turned off in the thoracic cavity.

gastric conduit was greatly reduced.

\section{Robotic thoracic dissection}

The robotic thoracic operation was done via full lateral position with cephalic-parallel approach as previously described (20). After completing mediastinal lymphadenectomy and mobilization of the esophagus, a $3.5 \mathrm{~cm}$ incision was created at the assistant port to facilitate creating the intrathoracic EGA. The esophagus was transected about $5.0 \mathrm{~cm}$ from the upper edge of the tumor, and the esophageal specimen was removed through the assistant incision.

\section{Pretreatment of the esophagus}

An atraumatic clamp (Aesculap, Germany) was placed at the proximal esophageal stump (about $3.0 \mathrm{~cm}$ to its margin) to reduce the bleeding caused by tailoring the esophageal stump. Incised the esophageal muscular layer about $0.5 \mathrm{~cm}$ from the esophageal stump while keeping the submucosa and mucosa intact. This procedure was completed using robotic scissors with its electronic coagulation function being turned off.

\section{Robot intrathoracic layered anastomosis}

(I) The gastric conduit was pulled up into the thoracic cavity by dragging the gauze surrounding it. Another atraumatic clamp (Aesculap, Germany) was placed at the distal gastrostomy site, the mucosal layer was cut open using robotic scissors with its electronic coagulation function being turned off (Figure 2). A transhiatal drainage tube served as a consecutive drainage device for the anastomotic site was also pulled up into the thoracic cavity with the conduit and connected to the extracorporal negative pressure aspirator through the abdominal incision.

(II) Sutured the posterior esophageal muscular layer and the posterior seromuscular layer of the conduit continuously using a 3-0 barbed suture (Stratafix, J\&J Co., USA) (Figure $3 A$ ).

(III) Tailored the proximal esophageal mucosa, the excess esophageal mucosal and muscular tissue was removed as the upper resection margin for intraoperative frozen inspection. Then, sutured the posterior esophageal mucosa and the posterior mucosa of the conduit continuously with 4/0 Vicryl plus antibacterial suture (J\&J Co., USA). After finishing, the ends of the thread were pulled tight (Figure 3B).

(IV) Sutured the anterior mucosa continuously with another 4/0 Vicryl plus antibacterial suture. Then the two running sutures were knotted with the each other to 
A

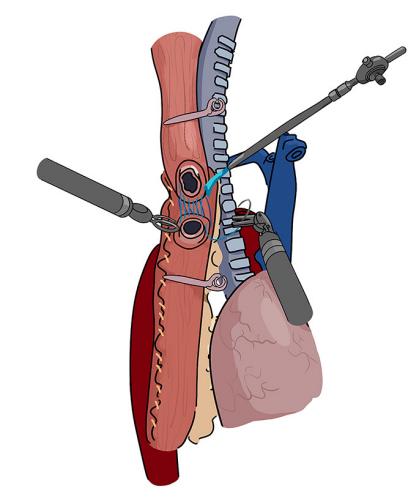

C

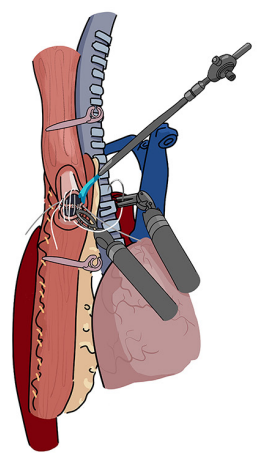

B

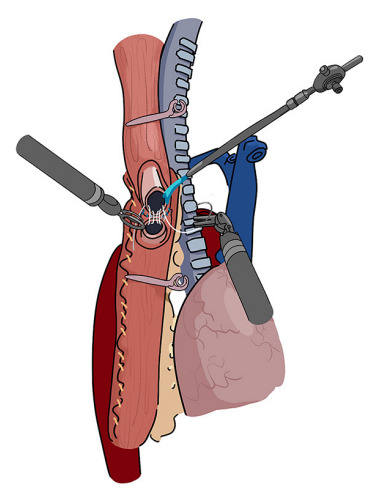

D

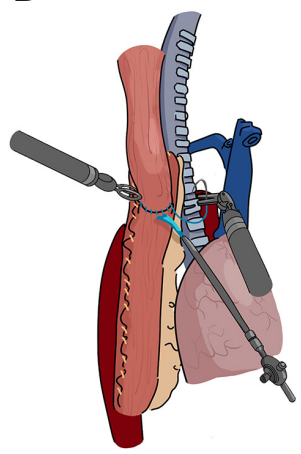

Figure 3 Scheme of the technique of the Robot intrathoracic layered anastomosis (an end-to-side hand-sewn EGA). (A) Suturing the posterior esophageal muscular layer and the posterior seromuscular layer of the gastric conduit; (B) suturing the posterior esophageal mucosa and the posterior mucosa of the gastric conduit; (C) suturing the anterior mucosal layer; (D) suturing the anterior muscular layer.

close the mucosal layer. During the anastomosis of the mucosa, the interculture distance and suture tension could be adjusted flexibly as needed (Figure 3C).

(V) Finally, removed the two atraumatic clamps and sutured the anterior muscular layer continuously with another 3-0 barbed suture (Stratafix, J\&J Co., USA) (Figure 3D).

During the anastomosis, for achieving precise suture, in addition to using atraumatic clamps, we also rinsed the anastomosis area intermittently using warm saline from 3-Liter bag outside the body to ensure the clearness of the surgical field. The anastomotic area was continuously drained by the transhiatal drainage tube.

After the anastomosis, only one $28 \#$ thoracic drainage tube was placed in the posterior mediastinum. No nutrient tube and anther drainage tubes were used in the operation. Selective en masse ligation of the thoracic duct was performed as previously described to prevent postoperative chylothorax (21).

\section{Postoperative care}

The patients were usually awakened in the operating room soon after the surgery and transferred to the ward. If postoperative resuscitation was not successful, the patient would be transferred to the intensive care unit for a smooth transition. Patients were mobilized for bedside activities on postoperative day 1 . Total parenteral nutrition was administered until the gastrointestinal function recovered and gradually transitioned to a semi-fluid diet.

\section{Comparison between the surgeon's early and late experience with PRILA}

The 43 patients who underwent PRILA were divided chronologically into two groups, classifying the operations completed within the first year as the surgeon's early experience group and the rest as the late experience group. The baseline, intraoperative characteristics, and 
Table 1 Baseline characteristics of the patients $(n=43)$

\begin{tabular}{|c|c|}
\hline Characteristics & Values \\
\hline \multicolumn{2}{|l|}{ Age, n (\%) } \\
\hline$\leq 60$ years & $17(39.5)$ \\
\hline$>60$ years & $26(60.5)$ \\
\hline Mean \pm SD & $62.60 \pm 7.135$ \\
\hline Median (min, max) & $64(50,74)$ \\
\hline \multicolumn{2}{|l|}{ Sex, n (\%) } \\
\hline Male & $33(76.7)$ \\
\hline Female & $10(23.3)$ \\
\hline \multicolumn{2}{|l|}{ BMI $\left(\mathrm{kg} / \mathrm{m}^{2}\right), \mathrm{n}(\%)$} \\
\hline$<18.5$ & $4(9.3)$ \\
\hline $18.5-23.9$ & $28(65.1)$ \\
\hline$\geq 24$ & $11(25.6)$ \\
\hline Mean \pm SD & $21.9 \pm 2.45$ \\
\hline Median (min, max) & $22.0(16.5,25.7)$ \\
\hline \multicolumn{2}{|l|}{ Tumor location, n (\%) } \\
\hline Mid-thoracic & $19(44.2)$ \\
\hline Lower-thoracic & $21(48.8)$ \\
\hline Esophagogastric junction & $3(7.0)$ \\
\hline \multicolumn{2}{|l|}{ Neoadjuvant treatment, n (\%) } \\
\hline Yes & $6(14.0)$ \\
\hline No & $37(86.0)$ \\
\hline \multicolumn{2}{|l|}{ Comorbidities, n (\%) } \\
\hline $\begin{array}{l}\text { Chronic obstructive pulmonary } \\
\text { disease }\end{array}$ & $5(11.6)$ \\
\hline Coronary arterial disease & $1(2.3)$ \\
\hline Hypertension & $5(11.6)$ \\
\hline Arrhythmia & $3(7.0)$ \\
\hline Kyphosis & $1(2.3)$ \\
\hline Nephrotic syndrome & $1(2.3)$ \\
\hline \multicolumn{2}{|l|}{ ASA, n (\%) } \\
\hline II & $28(65.1)$ \\
\hline III & $15(34.9)$ \\
\hline
\end{tabular}

postoperative outcomes were compared between the two groups. Postoperative complications were defined according to the Esophagectomy Complications Consensus Group (22).

\section{Statistical analysis}

Continuous variables were compared using the two-sample Student's $t$-test or the Mann-Whitney U test. Pearson's chi-square test or Fisher's exact test was used to compare the categorical variables between two groups. All statistical analysis was performed using IBM SPSS Statistics (version 26.0, IBM Corporation, Armonk, NY, USA). Two-sided $\mathrm{P}<0.05$ was considered statistically significant.

\section{Results}

\section{Baseline characteristics (Table 1)}

A total of 43 patients (33 males and 10 females) underwent PRILA from September 2018 to December 2020. The median age of these patients was 64 years (range, 50-74). Among them, 19 cases (44.2\%) were mid-thoracic esophageal cancer, 21 cases $(48.8 \%)$ were lower-thoracic esophageal cancer, and 3 cases (7.0\%) were esophagogastric junction cancer.

\section{Intraoperative characteristics and surgical outcomes (Table 2)}

All 43 patients underwent Ivor-Lewis MIE using PRILA technique with no conversions to thoracotomy. The mean total operation time was $384.42 \pm 75.235$ minutes, and mean intrathoracic anastomosis time was $48.23 \pm 14.565$ minutes. The 9th case developed postoperative small intestinal obstruction which was caused by jejunal volvulus confirmed by a second operation. After relieving the volvulus, he returned to normal and discharged on the 20th postoperative day. Thereafter, we abandoned routine jejunostomy in the subsequent cases. No anastomosis leakage was detected. Two cases suffered from anastomotic stricture, by placing the duodenal feeding tube and one endoscopic balloon dilatation, the two patients gradually returned to normal diet. Four patients $(9.3 \%)$ had transient hoarseness after surgery, but all recovered gradually. There was no 30-day mortality. All the patients were able to have a semi-fluid diet when discharged. The median postoperative stay was 10.0 days.

\section{Pathological outcomes (Table 3)}

The predominant histologic type was squamous cell carcinoma (38 cases, 88.4\%). All 43 patients underwent R0 
Table 2 Intraoperative characteristics and surgical outcomes $(\mathrm{n}=43)$

\begin{tabular}{|c|c|}
\hline Variables & Values \\
\hline \multicolumn{2}{|l|}{ Total operation time (min) } \\
\hline Mean \pm SD & $384.42 \pm 75.235$ \\
\hline Median (min, max) & $390.0(249.0,552.0)$ \\
\hline \multicolumn{2}{|l|}{ Anastomotic time, mean $\pm \mathrm{SD}$} \\
\hline Mean \pm SD & $48.23 \pm 14.565$ \\
\hline Median (min, max) & $45.0(28,84)$ \\
\hline Estimated blood loss $(\mathrm{mL})$, mean $\pm \mathrm{SD}$ & $110.47 \pm 96.435$ \\
\hline \multicolumn{2}{|l|}{ Jejunostomy, n (\%) } \\
\hline Yes & $9(20.9)$ \\
\hline No & $34(79.1)$ \\
\hline Conversion to thoracotomy, $\mathrm{n}(\%)$ & $0(0.0)$ \\
\hline Transfusion, n (\%) & $0(0.0)$ \\
\hline ICU stay (days), median (range) & $0(0$ to 6$)$ \\
\hline $\begin{array}{l}\text { Postoperative hospital stay (days), median } \\
\text { (range) }\end{array}$ & 10 (7 to 25$)$ \\
\hline \multicolumn{2}{|l|}{ Postoperative complications, n (\%) } \\
\hline Small bowel obstruction & $1(2.3)$ \\
\hline Anastomotic leakage & $0(0.0)$ \\
\hline Hoarseness & $4(9.3)$ \\
\hline Pneumonia & $3(7.0)$ \\
\hline Chylothorax & $0(0.0)$ \\
\hline Anastomotic stricture & $2(4.7)$ \\
\hline 30-day mortality, n (\%) & $0(0.0)$ \\
\hline
\end{tabular}

resection. Among the 6 patients who received neoadjuvant treatment, 2 patients achieved complete response. The mean number of totally resected lymph nodes was $17.42 \pm 6.926$.

\section{Comparison between the surgeon's early and late experience with PRILA (Table 4)}

There were no significant differences in baseline characteristics between the two groups. The total operation time and anastomotic time in the late experience group were significantly shorter than those in the early experience group (347.70 460.420 vs. $446.38 \pm 54.775$ minutes and $40.22 \pm 8.997$ vs. $61.75 \pm 11.969$ minutes, respectively; $\mathrm{P}<0.001)$. The late group harvested more lymph nodes compared with the early
Table 3 Pathological outcomes

\begin{tabular}{lc}
\hline Pathologic stages & Number $(\%)$ \\
\hline CR & $2(4.7)$ \\
pT1aN0 & $4(9.3)$ \\
pT1bN0 & $6(14.0)$ \\
pT1bN1 & $1(2.3)$ \\
pT1bN2 & $1(2.3)$ \\
pT2N0 & $1(2.3)$ \\
pT2N1 & $1(2.3)$ \\
pT2N2 & $1(2.3)$ \\
pT3N0 & $12(27.9)$ \\
pT3N1 & $3(7.0)$ \\
pT3N2 & $6(14.0)$ \\
pT4aN1 & $1(2.3)$ \\
ypT3N0 & $3(7.0)$ \\
ypT4aN1 & $1(2.3)$ \\
Histology type & \\
Squamous cell carcinoma & \\
Adenocarcinoma & $38(88.42 \pm 6.926$ \\
\hline CR 100.0$)$ \\
\end{tabular}

\section{Discussion}

In this report we shared our early experience of roboticassisted Ivor-Lewis esophagectomy using PRILA technique, which showed high feasibility and satisfactory surgical results without anastomotic leakage.

There have been several reports of robot hand-sewn intrathoracic EGA including a small number of patients (Table 5), but limited to a long learning curve, this technique has not been widely accepted so far. In 2013, Cerfolio (14) firstly reported this anastomotic method in their 16 early cases. However, in their subsequent cases the incidence of anastomotic fistula and gastric conduit necrosis was high, which was attributed to the lack of tactile feedback during the anastomosis. Then they switched to stapler anastomosis rather than hand-sewn anastomosis (23). In the Egberts' 
Table 4 Comparison between the surgeon's early and the late experience

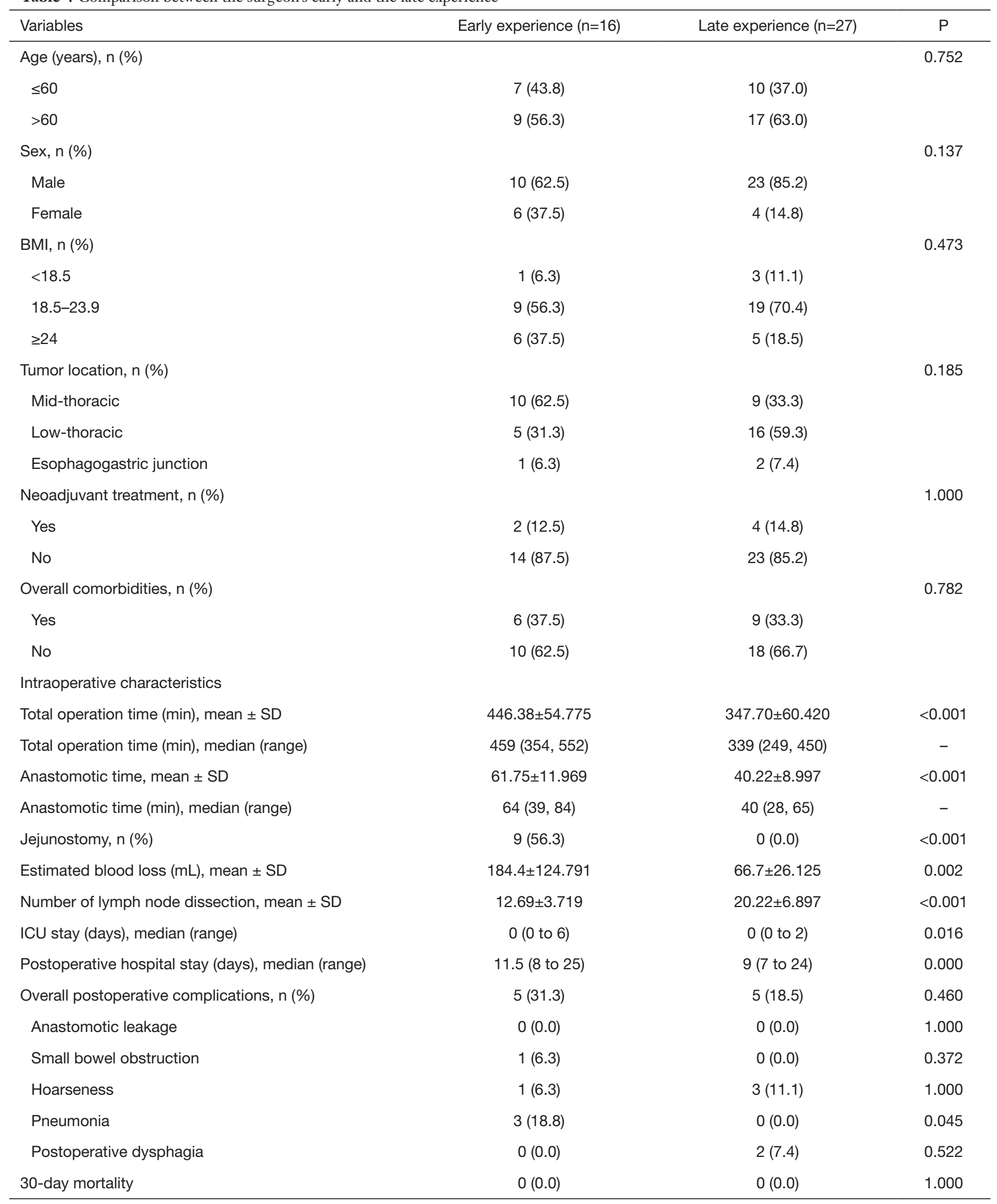




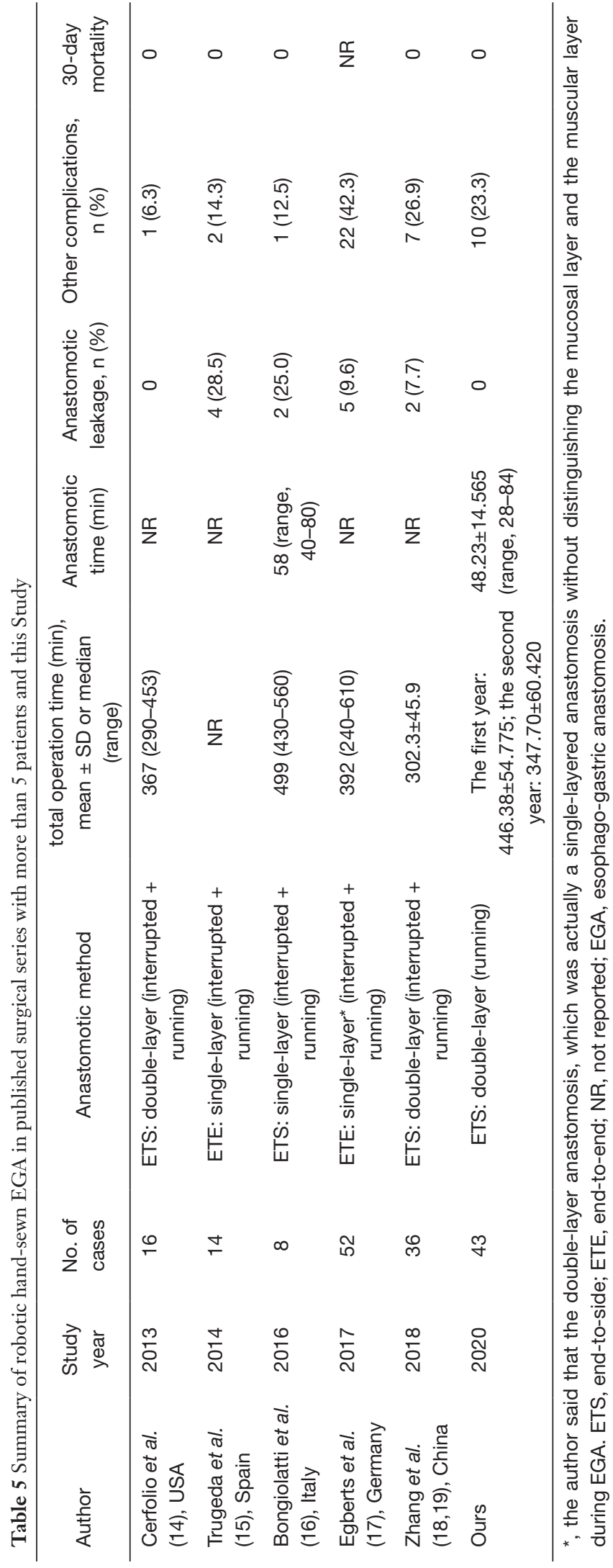

report of a two-layered suture of the back wall (17), they didn't distinguish the mucosal layer and the muscular layer during EGA, and the rate of anastomotic leakage was $9.6 \%$. After following up their subsequent relevant studies, we found that they were more inclined to circular stapler anastomosis now (24). In 2019, Zhang reported the biggest series of robot hand-sewn intrathoracic EGA including 36 patients in a single center in China up to now. According to their reports, the rate of anastomotic fistula was $7.7-8.3 \%$ $(18,19)$. To date, the technique of robotic hand-sewn intrathoracic EGA was still under exploration.

In our opinion, hand-sewn layered anastomosis is more precise and reliable. Comparing to single whole layer handsewn anastomosis or stapler anastomosis, the layer to layer manner (esophageal mucosal layer to gastric mucosal layer, esophageal muscular layer to the gastric seromuscular layer) restores the almost natural connection mode of the digestive tracts and reduces scar hyperplasia at the anastomotic site. And the use of Vicryl plus antibacterial suture for mucosa suturing might inhibit bacterial growth and reduce the inflammation at the anastomotic site (25). All of the above would be conducive to the healing of anastomosis and reducing the occurrence of postoperative anastomotic complications. Our center once reported 1,024 consecutive esophagectomy completed by this layered anastomosis method in open surgery, the incidence of anastomotic leakage and stricture was 0 and $0.6 \%$ (11). But under the conventional thoracoscopy, this procedure is too complicated to perform fluently due to the limitation of surgical field and operating space. With the help of the highly flexible robotic operating system, we developed the series technique called PRILA, making robotic intrathoracic EGA more precise and more fluent.

The pretreatment plays a great role in the precise intrathoracic EGA corresponding to the role of the threelobe forceps in open surgery (11). Firstly, the gastric conduit was tailored according to the landmark of sternal angle outside of the body. This method ensured the adequate length of a highly vascularized gastric conduit, and was also a simpler and less time-consuming procedure compared with tailoring the gastric conduit in thoracic cavity. Secondly, we used cold scissors to create gastrostomy and tailored the esophageal stump, avoiding the burning damages to the tissue in the anastomotic site. But at the same time, due to the lack of electrocoagulation function, the bleeding of submucosal vessels would interfere with the precise layer to layer anastomosis. Therefore, we put two atraumatic clamps (Aesculap, Germany) for a temporary 
occlusion at the proximal esophageal stump and the gastric conduit respectively to control the bleeding. What's more, during anastomosis, the surgical fields were rinsed intermittently with warm saline and continuously drained by a transhiatal drainage tube, to further maintain the clarity of the anastomotic region. Thirdly, the protection of gastric conduit was crucial to prevent conduit injury. During the pulling up of the conduit into the thorax, the warm wet gauze surrounding the gastric conduit functioned as a protective barrier reducing the mechanical injury to the fragile gastric conduit especially when it passed through the narrow esophageal hiatus. All the above pretreatment measures promoted the precise EGA. In our study, there was no anastomotic leakage occurred, which was better than other studies of robotic-assisted Ivor-Lewis esophagectomy.

Through continuous optimization of the surgical procedure and accumulation of experience, the total operation time has been shortened from the initial 7-8 hours to the current 5-6 hours. Now we could complete the EGA in 40 minutes. Moreover, the mean number of harvested lymph nodes was more $(12.69$ vs. $20.22, \mathrm{P}<0.001)$ in the late stage indicating a better oncologic results. Recurrent laryngeal nerve injury (4/40, 9.3\%) was the most common postoperative complication, which was related to a thorough dissection of recurrent laryngeal lymph nodes. But this was a temporary injury, which would gradually recover after the operation. No conversion and no 30-day mortality were found in our series.

Another point worth noting was that with the PRILA technique, we could complete EGA at the top of the thoracic cavity fluently and further extend the Ivor-Lewis MIE to some patients with mid-thoracic esophageal cancers, which was difficult to complete when using circular-stapled or linear-stapled anastomosis. In this study, patients with mid-thoracic esophageal cancer accounted for $44.2 \%$ $(19 / 43)$ of the total surgical cases.

This study had some limitations. First, due to the cost, not all the eligible patients in the same period received robotic surgery, which may result in selection bias, Second, the retrospective nature of the analysis and the limited number of cases from a single center should be noted. Third, only a small number of cases in this study underwent neoadjuvant treatment $(6 / 43,14.0 \%)$, which was different from other studies. Further multi-center, prospective clinical studies are warranted to further confirm the feasibility of the technique.

In conclusion, the series technique of PRILA further streamlines and visualizes the process of intrathoracic EGA, thus ensuring the precise anastomosis, which would be a feasible alternative for intrathoracic EGA in MIILE.

\section{Acknowledgments}

We thank Mr. Shi-De Wu from the High School Attached to Northeast Normal University for editing this manuscript. Funding: This work was supported by National Natural Science Foundation of China (No. 81672291, 31071210 to YD Lin).

\section{Footnote}

Reporting Checklist: The authors have completed the STROBE reporting checklist. Available at https://dx.doi. org/10.21037/jtd-21-438

Data Sharing Statement: Available at https://dx.doi. org/10.21037/jtd-21-438

Peer Review File: Available at https://dx.doi.org/10.21037/ jtd-21-438

Conflicts of Interest: All authors have completed the ICMJE uniform disclosure form (available at https://dx.doi. org/10.21037/jtd-21-438). YDL reports funding from National Natural Science Foundation of China (No. 81672291,31071210 to YDL). The other authors have no conflicts of interest to declare.

Etbical Statement: The authors are accountable for all aspects of the work in ensuring that questions related to the accuracy or integrity of any part of the work are appropriately investigated and resolved. The study was conducted in accordance with the Declaration of Helsinki (as revised in 2013) and was approved by the Ethics Committee of the West China Hospital of Sichuan University (No. 2020-323). Informed consent to undergo robotic surgery was obtained from all patients.

Open Access Statement: This is an Open Access article distributed in accordance with the Creative Commons Attribution-NonCommercial-NoDerivs 4.0 International License (CC BY-NC-ND 4.0), which permits the noncommercial replication and distribution of the article with the strict proviso that no changes or edits are made and the original work is properly cited (including links to both the formal publication through the relevant DOI and the license). 
See: https://creativecommons.org/licenses/by-nc-nd/4.0/.

\section{References}

1. Nozaki I, Mizusawa J, Kato K, et al. Impact of laparoscopy on the prevention of pulmonary complications after thoracoscopic esophagectomy using data from JCOG0502: a prospective multicenter study. Surg Endosc 2018;32:651-9.

2. Worrell SG, Bachman KC, Sarode AL, et al. Minimally invasive esophagectomy is associated with superior survival, lymphadenectomy and surgical margins: propensity matched analysis of the National Cancer Database. Dis Esophagus 2020;33:doaa017.

3. Sun HB, Li Y, Liu XB, et al. Embedded Three-Layer Esophagogastric Anastomosis Reduces Morbidity and Improves Short-Term Outcomes After Esophagectomy for Cancer. Ann Thorac Surg 2016;101:1131-8.

4. Zhang H, Chen L, Wang Z, et al. The Learning Curve for Robotic McKeown Esophagectomy in Patients With Esophageal Cancer. Ann Thorac Surg 2018;105:1024-30.

5. Qiu ML, Lin JB, Li X, et al. Current state of esophageal cancer surgery in China: a national database analysis. BMC Cancer 2019;19:1064.

6. van Workum F, van der Maas J, van den Wildenberg FJ, et al. Improved Functional Results After Minimally Invasive Esophagectomy: Intrathoracic Versus Cervical Anastomosis. Ann Thorac Surg 2017;103:267-73.

7. van Workum F, Berkelmans GH, Klarenbeek BR, et al. McKeown or Ivor Lewis totally minimally invasive esophagectomy for cancer of the esophagus and gastroesophageal junction: systematic review and metaanalysis. J Thorac Dis 2017;9:S826-33.

8. Li B, Yang Y, Toker A, et al. International consensus statement on robot-assisted minimally invasive esophagectomy (RAMIE). J Thorac Dis 2020;12:7387-401.

9. Hodari A, Park KU, Lace B, et al. Robot-Assisted Minimally Invasive Ivor Lewis Esophagectomy With Real-Time Perfusion Assessment. Ann Thorac Surg 2015;100:947-52.

10. Plat VD, Stam WT, Schoonmade LJ, et al. Implementation of robot-assisted Ivor Lewis procedure: Robotic hand-sewn, linear or circular technique? Am J Surg 2020;220:62-8.

11. Zhu ZJ, Zhao YF, Chen LQ, et al. Clinical application of layered anastomosis during esophagogastrostomy. World J Surg 2008;32:583-8.

12. Honda M, Kuriyama A, Noma H, et al. Hand-sewn versus mechanical esophagogastric anastomosis after esophagectomy: a systematic review and meta-analysis. Ann Surg 2013;257:238-48.

13. Wang F, Zhang H, Zheng Y, et al. Intrathoracic side-toside esophagogastrostomy with a linear stapler and barbed suture in robot-assisted Ivor Lewis esophagectomy. J Surg Oncol 2019;120:1142-7.

14. Cerfolio RJ, Bryant AS, Hawn MT. Technical aspects and early results of robotic esophagectomy with chest anastomosis. J Thorac Cardiovasc Surg 2013;145:90-6.

15. Trugeda S, Fernández-Díaz MJ, Rodríguez-Sanjuán JC, et al. Initial results of robot-assisted Ivor-Lewis oesophagectomy with intrathoracic hand-sewn anastomosis in the prone position. Int J Med Robot 2014;10:397-403.

16. Bongiolatti S, Annecchiarico M, Di Marino M, et al. Robot-sewn Ivor-Lewis anastomosis: preliminary experience and technical details. Int J Med Robot 2016;12:421-6.

17. Egberts JH, Stein H, Aselmann H, et al. Fully robotic da Vinci Ivor-Lewis esophagectomy in four-arm techniqueproblems and solutions. Dis Esophagus 2017;30:1-9.

18. Zhang Y, Xiang J, Han Y, et al. Initial experience of robotassisted Ivor-Lewis esophagectomy: 61 consecutive cases from a single Chinese institution. Dis Esophagus 2018. doi: 10.1093/dote/doy048.

19. Zhang Y, Han Y, Gan Q, et al. Early Outcomes of RobotAssisted Versus Thoracoscopic-Assisted Ivor Lewis Esophagectomy for Esophageal Cancer: A Propensity Score-Matched Study. Ann Surg Oncol 2019;26:1284-91.

20. Zhu Y, Ma L, Liu L, et al. Application of full lateral decubitus position with cephalic parallel approach in robotic-assisted minimally invasive esophagectomy. J Thorac Dis 2019;11:3250-6.

21. Lin Y, Li Z, Li G, et al. Selective En Masse Ligation of the Thoracic Duct to Prevent Chyle Leak After Esophagectomy. Ann Thorac Surg 2017;103:1802-7.

22. Low DE, Alderson D, Cecconello I, et al. International Consensus on Standardization of Data Collection for Complications Associated With Esophagectomy: Esophagectomy Complications Consensus Group (ECCG). Ann Surg 2015;262:286-94.

23. Cerfolio RJ, Wei B, Hawn MT, et al. Robotic Esophagectomy for Cancer: Early Results and Lessons Learned. Semin Thorac Cardiovasc Surg 2016;28:160-9.

24. Egberts JH, Biebl M, Perez DR, et al. Robot-Assisted Oesophagectomy: Recommendations Towards a Standardised Ivor Lewis Procedure. J Gastrointest Surg 2019;23:1485-92. 
25. Suárez Grau JM, De Toro Crespo M, Docobo Durántez F, et al. Prevention of surgical infection using reabsorbable antibacterial suture (Vicryl Plus) versus reabsorbable

Cite this article as: $\mathrm{Xu} Z \mathrm{ZJ}$, Zhuo ZG, Song TN, Li G, Alai GH, Shen X, Yao P, Lin YD. Pretreatment-assisted robot intrathoracic layered anastomosis: our exploration in IvorLewis esophagectomy. J Thorac Dis 2021;13(7):4349-4359. doi: $10.21037 /$ jtd-21-438 conventional suture in hernioplasty. An experimental study in animals. Cir Esp 2007;81:324-9. 